\title{
RESULT OF MINIMALLY INVASIVE PLATE OSTEOSYNTHESIS (MIPO) WITH USE OF LOCKING PLATE IN FRACTURE TIBIA DISTAL END
}

\section{Orthopaedics}

Dr. Kunal Shankar

MBBS, M.S. (Orthopaedics) [Hons.], Senior Resident, Department of Orthopaedics, Darbhanga Medical College \& Hospital, Laheriasarai, Bihar.

Dr. Vikash M. Harinandan* MBBS, M.S. (Orthopaedics), Senior Resident, Department of Orthopaedics,Darbhanga Dr. [Prof.] Laljee Medical College \& Hospital, Laheriasarai, Bihar. *Corresponding Author Chaudhary MBBS, M.S. (Orthopaedics), D.ortho., Professor and Head, Department of Orthopaedics, Darbhanga Medical College \& Hospital, Laheriasarai, Bihar.

\section{Dr. Debarshi Jana}

Young Scientist (DST), Institute of Post-Graduate Medical Education and Research, A.J.C. Bose Road, Kolkata-700020, West Bengal, India.

\section{ABSTRACT}

Background: The fractures of distal tibia including tibial pilon pose a great challenge to the surgeon due to subcutaneous location, scarcity of blood supply and paucity of soft tissue coverage. Minimal invasive plating osteosynthesis (MIPO) has evolved as a newer concept to treat distal tibial fractures with minimal articular comminution and minimal soft tissue damage. Aim of the present study was to evaluate the results of MIPO technique with use of a locking plate in fracture tibia distal end.

Method: During the study period of two years, total 45 cases of closed distal tibial fractures (Diaphyseal and metaphyseal region) were operated by MIPO technique with a distal tibial anatomical locking plate $(3.5$ and $4.5 \mathrm{~mm})$. They were followed up at regular intervals and results were evaluated.

Results: The age of the patients ranged from $20-60$ years with the majority $(19 ; 42.22 \%)$ of them being in the age of $40-50$ years. The most common mode of injury was road traffic accident (33; 73.33\%). In all patients MIPO was performed, in none of them, fracture site was opened. Mobilization of adjacent joints was carried out mostly from second to fourth postoperative day. Most of the fractures united between 10-12 weeks (26; $57.77 \%)$. On analyzing the results of MIPO, excellent results were seen in $66.66 \%$ cases and $33.34 \%$ had satisfactory results.

Conclusion: Hereby we concluded that though various modalities of treatment of fractures of the distal tibia are present MIPO seem to be better technique if done under skillful guidance as done in this study.

\section{KEYWORDS}

Fractures, Distal tibia, MIPO, Diaphyseal, Metaphyseal, Locking plate.

\section{INTRODUCTION}

Fractures of the distal tibia are complex injuries which remain a challenging proposition for treating Orthopaedic surgeon. These fractures are associated with severe soft tissue compromise and the involvement of the ankle joint further complicates these complex injuries. Numerous classifications have been proposed for these fractures; however, AO-OTA alphanumeric classification is the most comprehensive and commonly quoted classification. This led to a change in the philosophy of treating such injuries.

Several methods of treatment are implemented including nonoperative treatment, external fixation, intramedullary nailing, and internal fixation with traditional implants (standard screws and plates). However, each of these treatment options is associated with certain challenges. But currently, two methods are gaining popularity. On method is wire fixators, which is useful in highly comminuted fractures with significant soft tissue damage. Other is MIPO technique (Minimal invasive plating osteosynthesis) when there is minimal articular comminution and the soft tissue envelope is minimally damaged

MIPO is one of the latest few techniques of stabilization of proximal and distal ends of long bones e. g. Tibia, Femur. MIPO works on biological fixation principles in which blood supply to the fracture fragment is maximally preserved and percutaneously inserted plate is placed epiperiostally and fixed at a distance proximally and distal to the fracture site through minimal exposure. Its objective is to assist the physiological process of bone healing wisely and optimally with a minimal amount of operative intervention. However, compared with the traditional approach, minimally invasive techniques appear to have higher rates of the union, lower rates of postoperative complications and lower incidences of bone grafting. In this series, the results of 45 cases of fracture distal tibia treated with minimal invasive plating over a period of two years were studied.

\section{MATERIALS AND METHODS}

Total 45 patients with a closed fracture of Diaphyseal and metaphyseal region of the distal tibia treated using locking plate with MIPO technique during the period of two years from December 2017 to
November 2019 at Orthopaedics Department of Darbhanga Medical College and Hospital, Laheriasarai, Bihar were enrolled in the study. All patients with distal tibial fractures aged more than 18 years with Grade 1 compound fractures and complex ipsilateral injuries were included in the study. Patients with the distal neurovascular deficit, severe soft tissue injury, fracture of diaphysis of the tibia, previous osteomyelitis, grade 2 compound injuries and onwards, patients on immuno-suppressive therapy, patients with manifest infection, poor anesthetic risk and poor general condition were excluded from the study.

At the time of admission, the affected limb was stabilized with an above knee posterior slab and the patient was clinically and radiologically evaluated. The limb was elevated and appropriate analgesics were administered. The fracture was classified according to the latest AO classification while fractures of the distal tibia were classified by RUEDI and ALLGOWER based on the degree of articular and metaphyseal displacement and comminution. The line of treatment was decided according to the type of fracture, degree of displacement, depression and general condition of the patient. Majority of patients were operated between 3 to 10 days. Those patients who could not be operated early were mainly because of soft tissue compromise like massive swelling, the formation of blebs, etc or if associated with a head injury. In such a case Steinmann pin was inserted through calcaneum in case of distal tibial fractures. Then the patients were shifted in ward and limb was elevated in traction on Bohlers Splint.

All the patients were operated in a supine position under appropriate anesthesia under tourniquet. X-ray machine or image intensifier was so positioned that could be swiveled from AP to the lateral direction. Ipsilateral iliac crest and lower limbs were in draped and tourniquet inflated to $300 \mathrm{mg} \mathrm{Hg}$. Initial attention was given to fracture line which extended into Tibial Plafond and these articular fragments were reduced by $3.5 \mathrm{~mm}$ lag screw. Precontoured locking plates were used and incision of 2-3 cm over the anteromedial surface of the distal tibia was given and the plate was slid in and confirmed under X-rays in coronal and sagittal planes at level of the medial malleolus. The plate was stabilized to the shaft with adequate sized cortical screws to 
maintain interfragmentary compression and to increase the stability of the construct. Tourniquet was released and the wound was closed in layers.

Postoperatively the leg was maintained on an elevated position in an above knee plaster slab till the first wound check, which was done on day 3 post-operatively while the patient was in bed. Ambulation training was begun on a $1^{\text {st }}$ postoperative day in the form of toe-touch weight bearing with crutches. Patients were discharged from the hospital on an average of 5 days. Follow-up of the patients was kept at 2 weekly intervals for suture removal and thereafter for one month, three months and one year.

\section{OBSERVATIONS AND RESULTS}

In the present study, a total of 45 patients of fresh fractures of the distal tibia was treated by MIPO; among them 29 (64.44\%) were males and $16(35.55 \%)$ were females. The age of the patients ranged from $20-60$ years with the majority $(19 ; 42.22 \%)$ of them being in the age of $41-50$ years, (Table 1).

Table 1 : Age and sex Distribution

\begin{tabular}{|c|c|c|c|}
\hline Age (in years) & Males & Females & Total \\
\hline $20-30$ & $03(6.66 \%)$ & $00(0.0 \%)$ & $03(6.66 \%)$ \\
\hline $31-40$ & $09(20.0 \%)$ & $05(11.11 \%)$ & $14(31.11 \%)$ \\
\hline $41-50$ & $12(26.66 \%)$ & $07(15.55 \%)$ & $19(42.22 \%)$ \\
\hline $51-60$ & $04(8.88 \%)$ & $03(6.66 \%)$ & $07(15.55 \%)$ \\
\hline$>61$ & $01(2.22 \%)$ & $01(2.22 \%)$ & $02(4.44 \%)$ \\
\hline Total & $29(64.44 \%)$ & $16(35.55 \%)$ & $45(100 \%)$ \\
\hline
\end{tabular}

Out of 45 patients, 26 had a fracture on right and 19 on the left side. The most common mode of injury was road traffic accident in $33(73.33 \%)$ cases, fall in $10(22.22 \%)$ cases and direct trauma in $2(4.44 \%)$ of the cases. As per AO classification, most of the cases were of type A-1 i.e. 36 followed by A-2 i.e. 8 cases and A-3 being a single case.

Majority of patients had isolated distal tibia injury. 2 patients had a head injury and 2 had chest trauma. 3 patients had ipsilateral fibula fracture and 2 had ipsilateral femur fracture. Other associated injuries were shown in Table 2 .

Table 2 : Associated Injury

\begin{tabular}{|c|c|c|}
\hline Associated Injury & No. of cases & Percentage \\
\hline Head/Chest/Abdomen injury & 04 & $8.88 \%$ \\
\hline Ipsilateral lower limb & 05 & $11.11 \%$ \\
\hline Ipsilateral upper limb & Nil & 00.00 \\
\hline Contralateral upper/lower limb & Nil & 00.00 \\
\hline Pelvic/spine injuries & Nil & 00.00 \\
\hline
\end{tabular}

Postoperative complications observed were a superficial infection (1 case), deep infection (1 case) and non-union were seen in one patient. The period of hospitalization ranged from 5 to 21 days. The earliest union was seen at 10 weeks. Most of the fracture united between 10-12 weeks, (Table 3 ).

Table 3 : Period of Union

\begin{tabular}{|c|c|c|}
\hline Period & No. of cases & Percentage \\
\hline $10-12$ weeks & 26 & 57.77 \\
\hline $13-15$ weeks & 16 & 35.55 \\
\hline $16-18$ weeks & 03 & 6.66 \\
\hline
\end{tabular}

On analyzing the results of MIPO, excellent results were seen in $66.66 \%$ cases and $33.34 \%$ had satisfactory results.

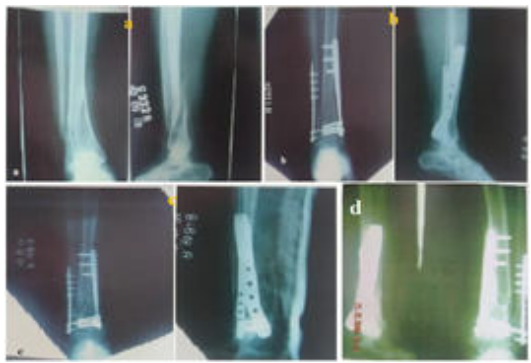

Figure 1: X-ray leg bones with ankle anteroposterior and lateral views (a) Preoperative views showing fracture distal end tibia (b) Immediate postoperative radiographs (c) At 3 months follow up and d) At 1-year follow up

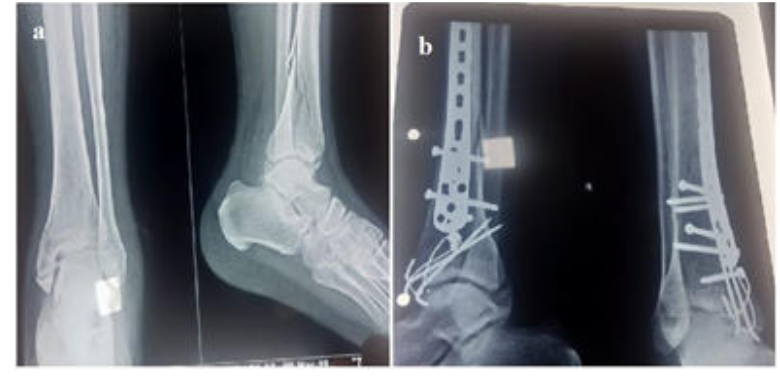

Figure 2: (a) Preoperative $x$-ray showing fracture of complex distal end (b) Immediate postoperative radiographs

\section{DISCUSSION}

Distal diametaphyseal tibia fractures are one of the most problematic injuries to manage. Results of operative treatment are dependent on the severity of the initial injury, the quality, and stability of the reduction. The mechanism of injury, the status of soft tissues, the degree of comminution and articular damage affect the long term clinical outcome. A variety of treatment options are available. But there is no consensus on the best treatment modality. Minimally invasive plating techniques reduce iatrogenic soft tissue trauma and damage to the vascularity of bone fragments, as well as preserve the fracture hematoma resulting in the uncomplicated union. Anatomical reduction of fractures should be done under image intensifier before fixation. In the present series, closed fractures of the distal tibia were treated by minimally invasive plate osteosynthesis.

The mean age of the patient was 42 years, ranged from 20-60 years which is comparable to the studies done by Patel et al and Daolagupu et al. Also, it was observed that a majority of patients were from the active stage of life i.e. 30-50 years. Male predominance observed in the study, it was probably due to more outdoor activities and heavier labor undertaken by males as compared to females in the Indian set up. This result is correlated with previous studies. Out of 45 patients, 26 had a fracture on right and 19 on the left side showing similarity with other studies.

In the course of present series, it was revealed that the most common mode of injury to the distal tibia was a road traffic accident, second most was fall on the ground and the least common was direct trauma/hit. Thus the road traffic accidents were predominate causing of the fractures and have been similarly reported by studies in Patel et al and Shabbir et al.

In the Helfet et al series, 20 patients had 12A-type 1-B type and 7 Ctype fractures two fractures were open i.e. both were Gustilo type 1. All fractures healed without the need for a second operation. In the study done by Gerber et al [20], all fractures were complex type-C according to $\mathrm{AO}$ classification. 15 out of 18 were closed fractures. While in present series all the fractures were of closed type. According to the AO classification, most of the cases were of type A-1 followed by A-2 and A-3. Minimal invasiveness in the treatment of these fractures resulted in early soft tissue revascularization, the early union of bone with abundant callus.

Among the 45 cases, 9 cases had multiple injuries; these were due to the involvement of these patients in road traffic accidents. We observed that the patients with associated injuries were difficult to mobilize and had comparatively higher morbidity. In the current study, it was found that on an average it took 11 weeks to resume full weight bearing. Patients with associated trauma were more morbid and hence difficult to mobilize with full weight bearing. This finding is comparable with those of standard series.

Total of 42 patients had good union without any complication. One patient had a superficial infection which was treated with debridement and dressing. Deep infection occurred in one case which was treated with debridement, dressing, and antibiotics. One case had non-union who was taken care of with postero-lateral bone grafting. Postoperatively, the majority of patients had ankle pain during mobilization but he was also dealt with vigorous physiotherapy and analgesics. This result of the complication is correlated with the other studies.

In the present series, the duration of the union of fractures of the tibia 
by minimally invasive plate osteosynthesis is better than other modalities of treatment, (Table 4).

MIPO technique was done in this series provides improved rates of fracture union, decreases the need for supplemental bone grafting, decreases the incidence of complications such as infection and refracture and preserves the vascularity of the fracture fragments. In MIPO as the fracture site is not exposed, the fracture hematoma is preserved and hence healing occurs with abundant external callus. These techniques have evolved in response to disappointing results following traditional methods of operative stabilization of the fractures of distal tibia and complications due to other modalities of treatment. In MIPO no prolonged splinting of the lower limb is required and hence lesser morbidity is the result. As the soft tissues are insulted minimally excellent healing is seen.

\section{CONCLUSION}

Early mobilization of the affected limb after stabilization of the fracture fragments as done in the present study which shown to reduce morbidity and therefore decreased the hospital stay thereby is saving the economy. Union rates of fractures were reduced which is comparable to fracture healing is by secondary intention. Various complications were comparatively less in this series and these could have been reduced by further experience in this technique.

Hereby we concluded that through various modalities of treatment of fractures of the distal tibia are present MIPO seem to be better technique if done under skillful guidance as done in this study.

\section{REFERENCES}

1. Akram W, Mahto AK, Alam M. Evaluation of results of minimally invasive plating osteosynthesis (MIPO) technique in the treatment of fractures of the distal tibia. Int JRes Orthop 2017;3:7-11.

2. Barie DP. Pilon fractures. In: Bucholz RW, Court-Brown CM, Heckman JD, Tornetta P Rockwood, and Green's Fractures in Adults, $7^{\text {th }}$ edition. Philadelphia: Lippincott Williams and Wilkins; 2010. Pp.1928-74.

3. Daolagupu AK, Mudgal A, Agarwala V, Dutta KK. A comparative study of intramedullary interlocking nailing and minimally invasive plate osteosynthesis in extra-articular distal tibial fractures. Indian JOrthop 2017; 51:292-8.

4. De Bastiani et al. Orthofix External Fixation in Trauma and Orthopaedics. Book January 2000, DOI: 10.1007/978-1-4471-0691-3; Publisher: 978-1-4471-1178-8.

5. Gerber C, Mast JW, Ganz R. Biological internal fixation of fractures. Arch Orthop Trauma Surg 1991: 109(6): 295-303.

6. Helfet DL, Suk M. Minimally invasive percutaneous plate osteosynthesis of fractures of the distal tibia. AAOS 2004; 53:471-475.

7. Kay L, Hansen BA, and Raaschou HO: Fractures of the tibial shaft conservatively treated. Injury 1986; 17:5-11.

8. Kretteck C. Concepts of minimally invasive plate osteosynthesis. Injury 1997; 28 (Suppl 1):805-809

9. Kumar D, Ram GG, Vijayaraghavan PV. Minimally invasive plate versus intramedullary interlocking nailing in distal third tibia fractures. IOSR J Dent Med Sci 2014; $13: 15-7$.

10. Leunig $\mathrm{M}$ et al. The evolution of indirect reduction techniques for the treatment of fractures. Clin Orthop 2000;375:7-14.

11. Mast JW. Reduction techniques in fractures of distal tibia auricular surface. Technique Mast JW. Reduction $20 \mathrm{chniques}$ in

12. Oh C-W et al. Percutaneous plating for unstable tibial fractures. J Orthop Sci 2003; 8(2):166-169

13. Patel YC, JangidAK and Patel CB. The outcome of minimally invasive plate osteosynthesis (MIPO) technique in distal tibial fracture. International Journal of Orthopaedics Sciences 2017;3(3): 10-14.

14. Ram GG, Kumar D, Phagal VV. Surgical dilemma's in treating distal third leg fractures. Int Surg J 2014; 1:13-6.

15. Reudi T, Allgower M. Fracture of lower end tibia into the ankle joint. Injury 1969; 1:92.

16. Rouk $\mathrm{O}$ et al. Minimally invasive plate osteosynthesis and vascularity: Preliminary results of a cadaver injection study. Injury supplement 1997; 28(1):7-12.

17. Ruedi TP, Allgower M. The operative treatment of intra articular fractures of the lower end of tibia. Clin Orthop. 1979; 138:105-10.

18. Salton HL, Rush S, Schuberth J. Tibial plafondfractures: Limited incision reduction with percutaneous fixation. J Foot Ankle Surg. 2007; 46(4):261-9.

19. Sarmiento A, Latta LL. 450 closed fractures of the distal third of the tibia treated with a functional brace. Clin Orthop Relat Res. 2004; 428:261-71.

20. Schatzker J. Osteosynthesis in trauma. Trauma International Orthop. 1992; 20:244252 .

21. Shabbir G, Hussain S, Nasir ZA, Shafi K, Khan JA. Minimally invasive plate osteosynthesis of close fractures of distal tibia. J Ayub Med Coll Abbottabad. 2011; 2:121-124.

22. Van der Linden $\mathrm{W}$ and Larsson $\mathrm{K}$. Plate fixation versus conservative treatment of tibial shaft fractures. A randomized trial. J Bone Joint Surg 1979; 61-A: 873-878.

23. Zelle BA, Bhandari M, Espiritu M, Koval KJ, Zlowodzki M. Evidence-based Orthopaedic Trauma working group. Treatment of distal tibia fractures without articular involvement: a systemic review of 1125 fractures. J Orthop Trauma 2006; (1):76-9. 